\title{
Discussion on Animation Education Reform in Undergraduate College
}

\section{Changrong Peng}

Department of Animation school, Hebei Institute of Fine Art, ShiJiaZhuang HeBei, 050700, China

123EEE@163.com

Keywords: Animation Industry, Education and Teaching, Reform measures

\begin{abstract}
Animation talent cultivation is basis for the development of animation industry, the shortage of talents become the major bottleneck to the industrial development. Animation undergraduate education is the base of personnel training, but unable to meet the market demand for talents for many reasons. Blind expansion the enrollment number and scale, resulting in the excess of personnel in some aspects, some aspects in the lack of talents. A large number of professional "top students" facing unemployment situation once graduated. Animation education and the actually need of the industry is out of proportion. To solve this problem, attempt to resolve the contradiction of the talents need in animation industry and college animation undergraduate education. Provide some ideas and methods to seek a suitable college animation undergraduate education.
\end{abstract}

\section{The current situation of the animation industry development in our research}

\section{The animation industry}

"Anime" the double meaning of the concept of the first meaning is refers to the "animation" and "comic" the combination of the two kinds of art form, this is our general understanding of; The second meaning refers to "dynamic cartoon" or "on the basis of cartoon animation," this is a deep understanding of comics. The second implication is that reveals the internal relation of animation and comic also represents the essential characteristics of animation art. Understand animation cartoon intrinsically linked to understand animation art is very important to the development of animation industry in China.

Definition of animation industry: Baidu encyclopedia for animation industry is defined as: " creativity" as the core, animation, comic as forms, including animation books, newspapers, movies, $\mathrm{TV}$, audio and video products, stage, and based on modern information communication technology of the cartoon and animation, such as direct product development, production, publishing, broadcasting, production and sales, related to the cartoon image and the clothing, toys, electronic games, such as the production and marketing of derivative products industry. Because has a broad prospects for development, animation industry is called emerging sunrise industry ? Animation industry is the creative power, on the basis of film and television culture, known as "smokeless industry" in modern society of ZhaoYang professional, it in the whole industry chain, not any natural environment destruction, it USES infinite originality consumers to recognize this authorization together with your completed. [1]

\section{Developed countries animation industry status quo}

"At present, the global animation industry has developed into big business groups and consumer market, formed the United States, Japan and Korea animation industry market pattern of the three pillars of the industry chain is very perfect, derivative product development is also very successful. According to statistics, in 2004, the world games, animation industry related derivatives output value of more than $\$ 500$ billion, among them, the digital entertainment industry output value accounts for 7.9\% of GDP, become the country's first big industry; the network game has 4 years in a row over Hollywood MaDian pictures, will become the largest entertainment industry; the Japanese game market each year to create the 2 trillion yen value scale, animation products export more than iron and steel exports. Even after the later of the south, anime products also accounted for $30 \%$ of global output, product is second only to the United States and Japan, South Korea one of the six pillar industries of national economy. " 


\section{Animation industry present situation in developing countries}

At present, the animation of the processing and production, outsourcing service is indispensable, in this process, the developed countries to develop the global market, to the original path. Animation processing state is scattered in the developing world, gradually transition to intensive service outsourcing, so with the help of some emerging countries gradually moves towards the original independent innovation path.

Developing countries to break the solution type: developing countries, such as Africa, Latin America and other countries, the animation industry has been developed countries rely on processing overseas animation to contracting type of order processing, there are few original animation works. As technology advances, these countries gradually animation processing to specification, animation industry is also in constant appreciation, domestic animation artist has been borrowed and appreciation value of the animation industry, and constantly looking for the path of the breakthrough. Coupled with the rich artistic and cultural resources in these areas, provide inexhaustible resources for the creation of the animation. [2] At present, almost without relying on the creation of the local culture, a lot of pure art short film has high artistic and aesthetic value. With the developed countries in stark contrast to the mainstream of the animation business type. Such as "jewish lion", "the birth of raila odinga's legend", greatly promote the industrial process of the countries in Africa and Kenya. But in Africa, Latin American folk art although brought them many development opportunities, but also experienced a long stage of development, to become their own cultural resources. Cheap Labour in Africa a lot of animation, become the industry in the developed countries of the transfer market, animation talent shortage, the government support fund shortage, reasons, such as the weakness of the animation industry in Africa. Many countries have already realized this problem, but the distance change this situation, still have a long distance. In India, Asia in the outsourcing of animation industry development mode has become increasingly mature. At present, India's animation company has independent intellectual property rights and the studio. India animation started very late, but is considered to be in the entertainment industry, one of the fastest developing areas. India as an international processing market outside, because have skilled technology, low cost and other advantages, have made great achievements. At present, the India animation still for outsourcing policy, but the future could change. Entertainment industry demand will increase from the following data to see the rapid development of animation industry in India, industry growth rate in 2006-2008 for $20.1 \%$, and so on, the animation industry in 2013 will reach 390 billion rupees. On the different links of animation industry chain, processing service, the fastest growth rate from 2009-2013, the compound annual growth rate will reach $17.8 \%$.

China's animation industry is gaining momentum, although in animation creation in our country has 80 years of history, but the animation industry really just starting from 2004. Before 2004, animation only "school", not "industry", the animation is as a genre of the movie, or a movie or television "genre", in the field of film marginalized. In 2004, the animation from a "school" into a creative, production, management and other economic benefits of the industry. "According to the state administration for industry and commerce of 27 provinces incomplete statistics, as of October 2006, the national animation of 5473 enterprises, 447 universities opened the animation specialty, involves 1230 universities start animation professional departments. By 2005, the country about anime professional and related professional graduates up to 6. 40000, 46 students. 6 people." Total domestic animation production is also increasing, "1993-2002 decade, China has reached 12000 minutes; domestic animation production in 2004, our country's animation production reached 21800 minutes.

\section{Animation college undergraduate course teaching in our country}

\section{Talent demand and post analysis}

At present, the animation industry as a new and fashionable industry, cultural industry in our country plays an increasingly important role. The whole animation industry, animation design and producer; Gap is huge, especially complex shortage of technical personnel and technology applied talents more. Under normal circumstances, about 20 minutes to make a $2 \mathrm{~d}$ animation, need 
professional and technical personnel 52 people. According to the average speed of animation process completed 6 minutes of class $C$, original painting set need 38 days, combined with previous work about two months to finish one episode. Shows, the production of animation is a labor-intensive industry and time. In addition, the animation technology updates very fast. Such as software upgrade, need practitioners even to attend training to improve themselves, to adapt to the development of industry and market changes. Animation industry chain is very long, which is very extensive, so the demand for talent is very rich also, from the senior management of the artist. Followed by marketing personnel, director of talent, until the primary technology talented person is a big gap. Animation in life is enjoyed by people and more and more attention, the application field of animation has been widening, in addition to the animation company, other industry is becoming more and more need to animation industry talents, therefore, demand for animation professional talents become more and more big. According to relevant data, in the next five years, our country existing enterprise of animation talent demand for 150000 people, animation production and technical personnel of the gap is bigger. [3] More concern is our country a lot of animation talents to 0 , it is unfavorable to the development of animation industry in China.

Pitchman serious shortage, especially the interdisciplinary talents and technology with a tree was a terrible shortage of, it has become one of the bottleneck of the animation industry development in our country. This contradiction makes the development of animation industry in China. Thus, animation and design personnel's demand is very big.

\section{The demand for marketing personnel, director, creative talents}

Generally speaking, the development of animation industry mainly need two people: one is the animation skills talents. Animation industry as the most potential industry in the world, in animation, media, film, television, advertising and other special planning has a huge market demand, need a lot of illustrators, story edition division, $2 \mathrm{~d}$ animators, $3 \mathrm{~d}$ animators, the role of the architect, scene simulation, the special effects production division, column packing division, industrial product designers, animation set division, cartoon artists of modeling of cartoon industry. Another kind of talent is the animation manufacture personnel, such as creative talents, the writers, marketing personnel, derivative product development, etc. Before a talents in colleges and universities undergraduate education more seriously, but for the latter is lack of talent is present. "Is mostly made of our numerous animation specialty in colleges and universities to cultivate talents. This phenomenon is not let us worry, is worth our reflection." Standing director of China animation association, such as wuhan Jiang Tong Zhu Youlan animation company chairman in an interview with reporters said: "look, domestic current high levels of animation creative talent, animation talents such as animation producer more scarce." , of course, the animation industry development is not only need technology talented person, even if is to master advanced technology to master the art talent cannot meet the needs of industrial development, because the operation of the industrial chain of animation industry development needs, and the industrial chain is made up of many links, such as mentioned above. State administration of radio, film and television advertising, the Jin Delong said: "the animation industry development of our country are in urgent need of three kinds of talent, namely: the creative research and development personnel, processing production personnel and business development talents. For a successful animation company, the early creative and business development in the late than the middle of the processed is more important." The so-called "three talents" is distributed on each link of industrial FaZhanLian.

Many people think of "pleasant goat and Wolffy bullish:" success is superficial, essence lies in film marketing. Responsible for the film of the Shanghai group operations center director willens $r$ $\mathrm{h}$ also emphasized the importance of marketing. Animation industry, in general, the party structure can be divided into three layers: the upper, middle and bottom. Senior mainly marketing planning, strategic management, and creative talents. At present, China's dire lack of high-level talents; Middle mainly technical talents, demand is big, is the largest power industry development; The bottom one is processing and operational personnel, demand is very big also, but now for saturated state; Therefore, animation talent structure is a pyramid, high-level talent shortages, marketing and maintenance of industrial chain of few and far between. 


\section{Animation undergraduate course teaching in colleges and universities}

Review of animation talents training course, can be divided into three stages: the first stage in the early 1950 s. 1950 money home, tragic Fan Jingxiang and so on one batch of animators in arts college "suzhou" animation professional teaching, have been recruited two students. Animation in 1952 the national colleges and universities teaching adjustment, merged with the Beijing film school, this batch of students graduating in 1953, after the suspension. Most of the teachers and students to enter art studio work, added a new for Chinese art film strength. The second phase in the early 1960 s. "Shanghai film school" was established in 1959, the school has set up animation specialty, money home lurid song-lin zhang ren, deputy director, director, cultivate professionals have a college degree. Shanghai film school has trained two students altogether, in 1961, graduated in 1963, stopped in 1963. , this batch of students also joined the "art studio" creative team. For thousand interference by "cultural revolution", the training of specialists in the field of animation work stopped more than ten years, a period. The third stage, after ten years of unrest in the $1980 \mathrm{~s}$, a large number of animation professionals to grow rapidly. In the $1990 \mathrm{~s}$, "the fine arts studios" take various forms to the training of specialists in the field of animation, first of all, the Beijing film academy JT? Set animation professional, is also the first animation degree education institutions in China, specially send professional teachers to teach and train a group of high level of animation. Second cooperation with Shanghai huashan middle school, the opening of a medium level of animation classes, a total of three classes, a total of create more than sixty animation professionals. The third is the animation workshops in the factory run, in the form of practice and learning, cultivate a group of young animation production personnel. Through the above three ways, but compared with developed countries, China's animation education seem to be too small, animation professional discipline construction is not perfect, particularly not formed systemic. After 2000 years, the rapid development of animation industry stimulated the growth of the animation education, according to 2003, the China animation association, the start animation professional specialized subject and undergraduate course colleges and universities a total of 93, there are about 7000 students in school. [4]In 2004, the state administration of radio, film and television at the Beijing film academy, the communication university of China, China academy of art and art institute of jilin animation college four colleges and universities, to establish the first animation teaching bases. In the same year in July, has risen to 171(table 1) and private training institutions also fosters the talent to help colleges and universities. At present, there are national 1200 JT? Set animation professional colleges and universities, nearly 1900 colleges and universities set up animation professional courses. Until today in the curriculum and teaching methods, also didn't realize animation teaching regularization. At present, the set animation professional colleges and universities can be divided into three categories, the first category for the film and television art college, such as north Beijing film academy, the central academy of drama, Beijing broadcasting institute, these colleges characteristics to make TV shows and art film, scripts, and writing. The second kind is pure fine arts colleges and universities, such as xi 'an academy of fine arts, sichuan fine arts institute, lu xun academy of fine arts and tianjin academy of fine arts, comic publications and image video editing features largely, multimedia technology mainly. The third class is a comprehensive university or normal colleges, such as chongqing university of posts and telecommunications, hainan university, xinjiang university, shaanxi normal university. Look from the number of open this professional bachelor of animation education in our country already had a big change, develop animation professional level of people, can be improved obviously, each presenting different features. Add a in the animation development power, but what makes domestic animation to commercialization, also need to redouble our efforts. 


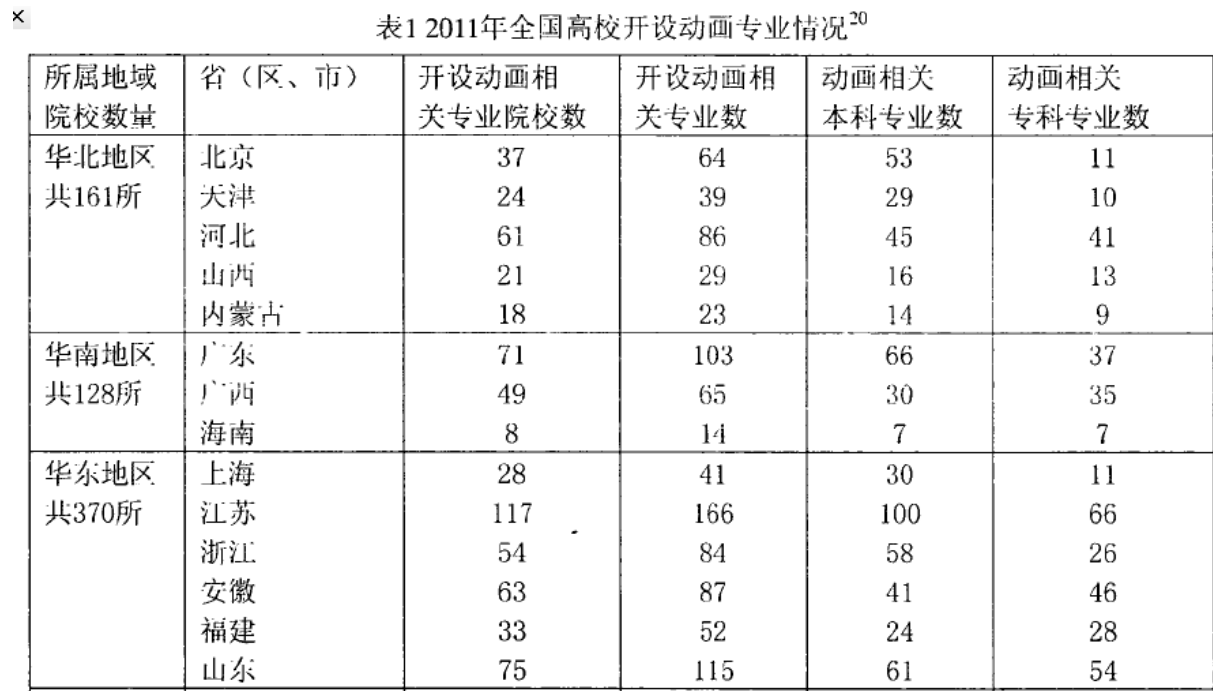

\section{Present situation analysis:}

Open animation professional colleges and universities continue to increase .At present, the animation staff of 40000 people, and the gap of 150000 . Opened in 2006, our country animation professional colleges and universities increased from two before 2000 to 447, opened and animation, comic book is more than 1230 by related departments; As of 2005, China's animation related professional graduates 64000 people, college students more than 466000 people; "By the end of 2009, according to data from the national open this specialized subject of colleges and universities of 1279 animation specialty, set up 1877 anime related field." ? Plus a number of relying on the animation enterprise run by the training institutions to open all the year round skills training, so the animation education scale is larger than animation industry in China, that is to say, in accordance with the scale of animation education in our country, the cultivation of professional person should be able to fully meet the needs of industry, and that is not the case. The relevant statistics, at present our country has 2000 provincial and municipal TV, animation channel 4, 25 children's channel,

Children's section 289, animation section 200, annual demand on animation is 26. Minutes, if the corresponding to the above, demand pitchman righteousness number should be in more than 150000 people. Although animation company needs a large number of talents, but beg to slam shut. Now the animation undergraduate enrollment scale expanding, born by training graduates don't meet the requirement of animation industry and couldn't find a job, the lack of animation, animation enterprise talent, no shortage of animation. One is the animation industry need a large number of talents; 2 it is to a large number of regular born graduates can't find a job, graduation means unemployment. Above is the animation education to cultivate talents in our country between both excess and deficiency, and industrial performance. [5]

Animation specialty in colleges and universities recruit students number and size of expanding from some aspect is also a graduate employment situation is not optimistic, according to "Chinese animation talent training normative research team to have a representative of the country's opening animation and animation related survey data of 54 universities, graduates of colleges and universities in the animation companies accounted for $27 \%$, the game company and Internet company each accounted for $15 \%$ and $8 \%$, how the market demand and the animation undergraduate education quality to seek a balance become a problem to be solved. Here is the 2011 national college set animation professional situations:

Table 12011 national college offers animation professionals

The single teaching mode, training target is not clear and the curriculum system is not standard

Teaching work in colleges and universities in our country has always been a basic approach to the implementation of school education, teaching system in our country for many years has formed a relatively fixed teaching methods and teaching mode. Since the reform, the teaching in colleges and universities also in the reform, it also become the focus problem. To perfect the teaching reform, colleges and universities and make great efforts in many ways, and JT set up some new subjects, 
animation professional is growing up in the teaching reform. As is known to all, the animation specialty is an interdisciplinary, special compound, the above animation professional redundant set time is not long, in our country in the last century animation professional open only in some vocational colleges, opening animation specialty in college undergraduate course is in recent years. Therefore, animation undergraduate teaching is used the traditional teaching mode and teaching method.

Teaching mode in the four-year undergraduate teaching in colleges and universities, there is a situation:

(1) as the recruitment of students scale expands gradually, professional art before several or a dozen students in a classroom, it can guarantee the quality of the arts students, and now many colleges and universities design, animation professional recruitment of students scale is too large, the course can only execute large class, dozens of students and even a classroom -? A studio for specialized course learning. Such as xinjiang set animation professional art academy in 2003, the first batch of students for the 9, 2007, the nine students graduate, respectively, in shenzhen universal digital painting design, network product in Beijing do network animation, game animation in Shanghai, a training school in Beijing in $3 \mathrm{~d}$ software teaching, a college graduate, was admitted to the China central academy animation back to xinjiang art college in 2011, a professor at the animation, and one went to jiangxi normal college as animation teacher, only two students turned, from the point of their employment, or very good. Until 2011, xinjiang academy of arts animation is 36 people, a class of 36 people in a classroom, Shared a studio, a teacher in the face of dozens of students in this case, how can teachers teaching quality guarantee? How can their aptitude?

(2) the single teaching mode, four years of undergraduate study, the first year is drab sketch and color basic course training, they have no purpose to practice painting, the basis of not know what to do with painting these foundation, learning is no power, there is no basic drawing and animation professional class, so that the painting of the basic course for the future of the course does not work. Through two years of animation teaching, the students told me that when a freshman learning sketch on colour, they feel very lost and don't know what to draw it to, does not have any power.

(3) the theory and practice is not very good. Colleges and universities animation professional training of students would not align with company demand, only pay attention to the study of the theory of college students in the school, poor practice ability.

(4) the curriculum system setting is not standard. At present our country both in professional colleges and universities and comprehensive universities to establish the animation specialty, animation course is the foundation of the animation specialty teaching. The present increase year by year, the number of enter oneself for an examination even employment outlook is not optimistic. Why is this case? One reason is that students of art of animation professional entrance examination basis is lower than the traditional painting professional, academic requirements are lower than other liberal arts examinee, this creates the "non-artistic", "the culture" of the students to enter oneself for an examination professional animation. Arts examinee academic scores are relatively low, also said liberal arts examinee 100 points can enter a key university, and the arts professional candidates also need to take an examination of 70 points can enter this university. As a result, many students are in order to be admitted to the university, a temporary adjustment to learn art, enter oneself for an examination the temporary remedial class learning sketch and color, the training time is shorter, learning objectives are not clear. Because many candidates just blindly choose animation major for college, have accepted by most of the arts examinee basic skill is weak, lack of professionalism, just mix diploma phenomenon is very serious.

\section{Discussion on animation undergraduate course teaching reform in colleges and universities}

\section{Reform measures}

According to the analysis of the current situation of the animation undergraduate teaching in colleges and universities, to find a lot of problems, then puts forward some teaching reform measures to solve these problems are as follows:

Pass of the college entrance examination, improve the quality of students. In colleges and 
universities to adjust and improve the animation talents education teaching plan, before looking for training professional talents mode, first for talent selection mechanism and the college entrance examination enrollment policy reform. Pass of recruit students, to improve the quality of students as the basis of the reform, first of all, to improve the examination subjects, most colleges and universities to take an examination of the sketch, color only to open the sketch, color, sketch, write, and test, the lack of interest in art and quality, the strength is not solid examinee filter, for those who have artistic talent and potential candidates to provide the opportunity to study better. Secondly, properly raising the grade of the raw mix of fine arts, the opportunity to reduce the speculation.

Control the enrollment scale and quantity, amount and scale and the animation education in colleges and universities gradually rise, graduates each year graduation will face unemployment, employment situation is not very optimistic, so now we should be more interested in the quality of education. First from the competent authorities, should control recruit students number and size, relative professional universities animation is now in extensive training talents, rather than against targeted, to training, graduate employment can't adapt to enterprise demands and turned, or unemployment. After the extensive development of wave, perhaps the next trend will be the reform of animation and readjusting disciplines. Integration refers to the disorderly development stage is not reasonable, planning or the place of removal. For the large number of recruitment of students scale should be cut a lot. And course reform is based on the characteristics of universities, combining own teaching experience, trying to find accord with the characteristics of their own goals and direction. Should avoid blindly, film and television animation training of talents, broaden the vision, absorb the experience of foreign universities, the teaching reform actively. The ministry of education, the government and universities faculty should also be rational at the cartoon art and animation industry, responsible for the industry development and responsible attitude to the student, not only pay attention to the enrollment of colleges and universities, only interests, and should be people-oriented, animation and improve the teaching level.

To strengthen the teachers, improve the quality of teaching.

(1), teacher training. Colleges and universities should have long-term teachers construction planning and the recent goals, have to absorb talents, cultivating talents and the stable talented person's mechanism. In curriculum construction and course construction to promote the construction of teachers, to improve the level of scientific research and teaching quality. Improve the teachers' knowledge structure, enhance the teaching ability for the principle, in order to promote the improvement of teachers. First of all, the teachers and students proportion of reasonable structure, meet the requirements of job of undergraduate course teaching, the general situation is not higher than 1:16, teacher-student ratio = total number of teachers/undergraduate students. Teacher 2 total number of full-time teachers + number of part-time teachers. Secondly, the teachers troop overall structure is reasonable, has good development trend, in line with the professional target, to adapt to the professional and long-term development needs of the subjects and the teaching needs. Teachers' age structure more reasonable, under the age of 40, an associate professor and professor under the age of 55 respectively appropriate to associate professor and professor of proportion, the proportion of middle-aged and young teachers should be in the majority. Finally, teacher's title and the degree of structure shall be reasonable. A lecturer at the above title and soil degree to recognize more than the proportion of teachers should be higher than $85 \%$.

(2) to teacher's knowledge structure, ability and quality requirements. The teachers' academic level: according to the construction of the animation specialty, curriculum construction and the needs of the development of disciplines, full-time teachers should accelerate the update of professional knowledge,. Broaden the related professional knowledge, have higher ability of scientific research, teaching and creation. Foreign language ability: the teacher should have strong ability of foreign language, can have the basic ability to international communication. Application ability of teaching means, teachers can master modern teaching method, and combined with the traditional teaching means to improve teaching efficiency; Attaches great importance to the teaching level and the study of teaching methods. 
(3) assistant post Settings. According to the characteristics of the number of students and course configuration just the right amount of ta, ta can help the speaker practice under the guidance of teachers, guidance on operation, solve students' answering questions, can achieve better teaching quality. Set up the teaching monitoring system to ensure that the teaching quality, promote the standardization of the teaching quality and scientific.

\section{Teachers should pay attention to teaching methods}

In classroom teaching, teachers should be emphasis and highlight the difficulty, combined with the actual case to strengthen the mastery of professional theory of life. Should use discussion-based classroom teaching, heuristic teaching methods to mobilize students' initiative and creativity in animation professional study. Class should be appropriate to carry out projects discussion, group activities, and debate to active classroom atmosphere to enhance students' interest in learning in a professional, strengthen students' learning initiative.

\section{Emphasis on teachers' mastery of new technology}

The current animation specialty is the traditional animation and computer animation and new media art direction. Animation major should make full use of traditional animation and computer technology combined with the advantages of teaching, such as, in the animation talent training, the study involves consideration of the new technology on film, games, multimedia, and other fields, also should pay attention to the study of relevant theories.

\section{Pay attention to the artistic practice in teaching}

Animation professional teaching should pay attention to the artistic practice, whether it is work, teaching and examination forms, all want to emphasize the students' practical ability, practice teaching link should account for $6 \%$ of the total class hours, practice and hands-on ratio should be 1:1. Teachers should pay more attention to case teaching in the process of teaching, examination of each course and class methods can adopt the way of creating animation works. Outside the classroom, organizes the student to the field sketch to the studios and companies are art practice. Animation professionals are the traditional features of teaching practice, teachers should pay close attention to the current animation technology, the arts, the latest dynamic theory and market and so on, provide students with the new information. Should make full use of the animation professional discipline superiority, the establishment of practice base outside the school in order to promote the students' practical needs.

\section{References}

[1] Tan Ling, YanJun. Animation industry [M]. Chengdu: sichuan university press, 2006.

[2] Wang Jizhong. Animation industry operating and management [M]. Beijing: the communication university of China publishing house, 2006.

[3] Jia Fou, Lu Shengzhang. Introduction to animation [M]. Beijing: the communication university of China publishing house, 2005.

[4] Annual report for animation industry group. Annals of the animation industry [M] ocean press, 2006.

[5] Qin Xijie. Chinese animation industry economics research [M]. Beijing: China publishing house, 2006. 